\title{
Agathidium from Nepal collected \\ by Dr. A. Smetana, with description of a new species (Coleoptera, Leiodidae, Anisotomini)
}

by

\author{
Fernando ANGELINI * et Luigi DE MARZO * *
}

With 7 figures

ABSTRACT

Field data are presented on 230 specimens, 17 species, of Agathidium, recently collected by Dr. A. Smetana in Nepal. Agathidium querceum n. sp. is described.

\section{INTRODUCTION}

This further contribution to the knowledge of the Nepalese fauna of Anisotomini deals with 230 specimens of the genus Agathidium, which have been collected by Dr. Ales Smetana (Ottawa) in April and May 1985. They belong to 17 species, including a new one, Agathidium querceum n. sp., which is described here.

The specimens are deposited in the Museum of Natural History of Geneva (MHNG) and in Angelini's collection (AC).

\section{Agathidium (s. str.) subopacum Ang. \& Dmz.}

Agathidium (s. str.) subopacum Angelini \& De Marzo, 1981: 227; 1983a: 161; 1983b: 156; 1985: 44.

Material: Nepal, Bagmati prov., Kathmandu distr., Siwapuri Dara, 2300-2500 m, 29.IV-3.V.1985, leg. A. Smetana, 10 exx. in MHNG, 3 exx. in AC.

* Via Imperiali 203, I-72021 Francavilla Fontana, Brindisi, Italy.

** Istituto di Entomologia Agraria e Forestale dell’Università di Basilicata, via N. Sauro 85, I-85100 Potenza, Italy. 
Collecting methods: Sifting mosses, plant debris, barks, dead leaves and soil under tree trunks in forests of oak-trees and rhododendrons.

Distribution: Nepal, India (Uttar Pradesh and Darjeeling), Bhutan.

Agathidium (s. str.) nivale Ang. \& Dmz.

Agathidium (s. str.) nivale Angelini \& De Marzo, 1981: 223; 1983a: 159; 1983b: 156; 1985: 45.

MAterial: Nepal, Bagmati prov. Rasuwa distr., north slope above Syabru, 3600-3800 m, 19.IV.1985, leg. A. Smetana, 4 exx. in MHNG, 1 ex. in AC; Bagmati prov., Kathmandu distr., Siwapuri Dara, 2300-2500 m, 29.IV-3.V.1985, leg. A. Smetana, 25 exx. in MHNG, 6 exx. in AC.

Collecting methods: Sifting mosses and plant debris under a fallen tree, soil at the base of bushes, litter and barks of fallen trees in forest of oak-trees and rhododendrons.

Distribution: Nepal.

Agathidium (s. str.) smetanai Ang. \& Dmz.

Agathidium (s. str.) smetanai Angelini \& De Marzo, 1985: 47; 1987: 457.

MAterial: Nepal, Bagmati prov., Nuwakot distr., between Ghopte and Thare Pati, 31503250 m, 23-25.IV.1985, leg. A. Smetana, 17 exx in MHNG, 5 exx. in AC.

Collecting methods: Sifting mosses, plant debris and litter in forest of fir-trees, maples and rhododendrons.

Distribution: Nepal.

Agathidium (s. str.) apterum Ang. \& Dmz.

Agathidium (s. str.) apterum Angelini \& De Marzo, 1981: 232; 1985: 49; 1986: 848.

MAterial: Nepal, Bagmati prov., Nuwarot distr., between Ghopte and Thare Pati, $3200 \mathrm{~m}$, 23-24.IV.1985, leg. A. Smetana, 2 exx. in MHNG, 2 exx. in AC.

Collecting methods: Sifting mosses, plant debris and litter in forest of fir-trees and rhododendrons.

Distribution: Nepal, India (Darjeeling).

Agathidium (s. str.) bagmaticum Ang. \& Dmz.

Agathidium (s. str.) bagmaticum Angelini \& De Marzo, 1985: 52.

Material: Nepal, Bagmati prov., Nuwakot distr., between Ghopte and Thare Pati, $3200 \mathrm{~m}$, 24-26.IV.1985, leg. A. Smetana, 5 exx. in MHNG, 2 exx. in AC.

Collecting methods: Sifting mosses, plant debris and litter in forest of fir-trees and rhododendrons.

Distribution: Nepal. 
Agathidium (s. str.) fulungense Ang. \& Dmz.

Agathidium (s. str.) fulungense Angelini \& De Marzo, 1981: 236; 1983a: 166; 1987: 458.

MAterial: Nepal, Bagmati prov., Rasuwa distr., north slope above Syabru, 3600-3800 m, 18-19.IV.1985, leg. A. Smetana, 9 exx. in MHNG, 4 exx. in AC; Bagmati prov., Nuwakot distr., between Ghopte and Thare Pati, 3200 m, 23.IV.1985, leg. A. Smetana, 3 exx. in MHNG, 1 ex. in AC.

Collecting methods: Sifting mosses and plant debris under a fallen tree, decaying wood, plant debris and litter in forest of fir-trees and rhododendrons.

Distribution: Nepal.

Agathidium (s. str.) visnu Ang. \& Dmz.

Agathidium (s. str.) visnu Angelini \& De Marzo, 1985: 54.

Material: Nepal, Bagmati prov., Kathmandu distr., Siwapuri Dara, 2300-2500 m, 29.IV-3.V.1985, leg. A. Smetana, 30 exx. in MHNG, 10 exx. in AC.

Collecting methods: Sifting mosses, plant debris, barks, leaves and soil under fallen trees in forest of fir-trees and rhododendrons.

Distribution: Nepal.

Agathidium (s. str.) kathmanduense Ang. \& Dmz.

Agathidium (s. str.) kathmanduense Angelini \& De Marzo, 1981: 255; 1985: 57; 1986: 851; 1987 : 458.

Material: Nepal, Bagmati prov., Kathmandu distr., 2300-2450 m, 29.IV-3.V.1985, leg. A. Smetana, 2 exx. in MHNG, 2 exx. in AC.

Collecting methods: Sifting mosses, plant debris and litter in forest of oak-trees and rhododendrons.

Distribution: Nepal.

Agathidium (s. str.) querceum n. sp.

(Figs 1-7)

Length 3,4-3,5 mm (holotype o 3,4 mm). Dorsum black, reddish-brown at sides of pronotum and elytra; venter reddish-brown; antennae without darker club; legs testaceous. Microreticulation superficial and uniform on head and pronotum, absent on elytra; whole dorsum with fine and sparse puncturation.

Head: Microreticulation superficial and uniform. Punctures small and superficial, spaced from each other by 1-5 times their own diameter. Clypeal line absent. 3rd antennal segment 2,3 times as long as the 2nd and longer than 4th + 5th (Fig. 1); Hamann's organ: gutter without vesicles in both 9th and 10th antennal segments.

Pronotum: Microreticulate as head. Punctures as those of head. 1,4 times as broad as head, moderately transverse $(\mathrm{W} / \mathrm{L}=1,6)$ and very convex $(\mathrm{W} / \mathrm{H}=1,44)$. Dorsal and lateral outlines: figg. 2 and 3. Holotype: length 1,08 mm, width 1,73 mm, height 1,20 mm. 


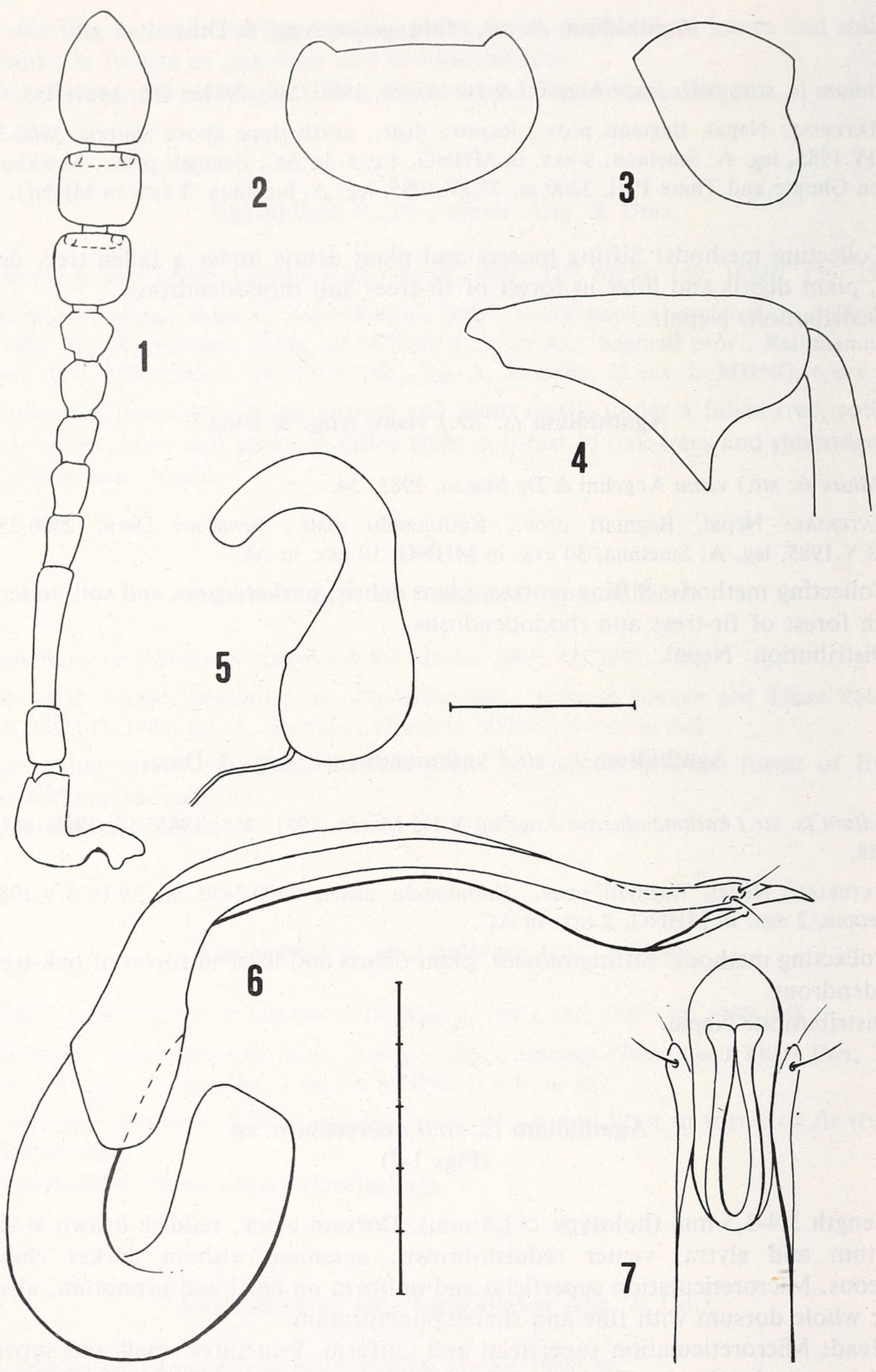

Figs 1-7.

Agathidium querceum n. sp.: 1, antenna; 2-3, dorsal and lateral view of pronotum; 4, male hind femur; 5 , spermatheca; 6-7, male copulatory organ, lateral view and ventral view of apex. Scales: 1 division $=0,1 \mathrm{~mm}$. 
Elytra: Microreticulation absent. Punctures a bit larger than those of pronotum, spaced from each other by 1-5 times their own diameter; some larger punctures are interposed. A little narrower than pronotum, as long as broad and moderately convex $(\mathrm{W} / \mathrm{H}=1,71)$. Lateral outline with very slight humeral angle. Sutural striae absent. Holotype: length $1,52 \mathrm{~mm}$, width $1,65 \mathrm{~mm}$, height $0,96 \mathrm{~mm}$.

Metathoracic wings absent. Meso- and metasternum: median carina weak, lateral lines absent, femoral lines incomplete.

Legs: Male hind femora with a large thoot (Fig. 4). Tarsal formula: o 5-5-4, ९ 5-4-4.

Male copulatory organ (Figs 6 and 7): Aedeagus slender, with hook-like proximal part, lateral margins sinuate, rounded apex; ventral piece with arms thin and distally enlarged. Parameres thin, not expanded towards their apex.

Spermatheca (Fig. 5): Basal part pear-shaped; apical part slender, truncate at apex.

Discussion: A. querceum n. sp. is closely related to A. fulungense Ang. \& Dmz. owing to habitus and microreticulation characters; it differs from the latter in ratio $3 \mathrm{rd} / 2$ nd of antennal segments, shape of hind femora, apex and ventral piece of aedeagus.

Collecting methods: Sifting mosses, plant debris and litter in forest of oak-trees and rhododendrons.

TyPES: Nepal, Bagmati prov., Kathmandu distr., Siwapuri Dara, 2300-2500 m, 29-30.IV and 3.V.1985, leg. A. Smetana, $1 \sigma^{\circ}$ holotype N.6130, $1 \sigma^{\prime}$ paratype N.6132 and 1 \% paratype N.6134 in MHNG, $1 \%$ paratype N.6131 and 1 \% paratype N.6133 in AC.

Distribution: Nepal.

Agathidium (s. str.) fulgens Ang. \& Dmz.

Agathidium (s. str.) fulgens Angelini \& De Marzo, 1985: 57; 1986: 852.

MAterial: Nepal, Bagmati prov., Rasuwa distr., Langtang Khola valley, 2,5 Km east from Syabru, 1720 m, 14.IV.1985, leg. A. Smetana, 1 ex. in MHNG.

Collecting methods: Sifting plant debris and fallen branches at the base of rocks.

Distribution: Nepal.

Agathidium (s. str.) siva Ang. \& Dmz.

Agathidium (s. str.) siva Angelini \& De Marzo, 1985: 57.

Material: Nepal, Bagmati prov., Nuwakot distr., 3200 m, 23-24.IV.1985, leg. A. Smetana, 12 exx. in MHNG, 5 exx. in AC; Bagmati prov., Kathmandu distr., Siwapuri Dara, 2400-2500 m, 29.IV-2.V.1985, leg. A. Smetana, 26 exx. in MHNG, 7 exx. in AC.

Collecting methods: Sifting mosses, plant debris, barks of fallen trees and soil under the latter, in forests of fir-trees, oak-trees and rhododendrons.

Discussion: This is the second report of this species, of which only the three types were known so far.

Distribution: Nepal. 
Agathidium (s. str.) circumflexum Ang. \& Dmz.

Agathidium (s. str.) circumflexum Angelini \& De Marzo, 1981: 259; 1983a: 172.

Material: Nepal, Bagmati prov., Nuwakot distr., between Ghopte and Thare Pati, $3200 \mathrm{~m}$, 23.IV.1985, leg. A. Smetana, 2 exx. in MHNG, 1 ex. in AC; Bagmati prov., Kathmandu distr., Siwapuri Dara, 2300-2450 m, 29.IV-3.V.1985, leg. A. Smetana, 5 exx. in MHNG, 2 exx. in AC.

Collecting methods: Sifting mosses, plant debris and litter in forests of fir-trees, oaktrees and rhododendrons.

Distribution: Nepal.

Agathidium (s. str.) franzi Ang. \& Dmz.

Agathidium (s. str.) franzi Angelini \& De Marzo, 1981: 260; 1983a: 172; 1986: 854; 1987: 458.

Material: Nepal, Bagmati prov., Rasuwa distr., Langtang Khola valley, Forest Camp, 1950 m, 13.IV.1985, leg. A. Smetana, 1 ex. in MHNG; Langtang Khola valley, 2,5 Km east from Syabru, 1700 m, 14.IV.1985, leg. A. Smetana, 1 ex. in AC.

Collecting methods: Sifting soil and plant debris at the base of roks.

Distribution: Nepal.

\section{Agathidium (s. str.) paria Ang. \& Dmz.}

Agathidium (s. str.) paria Angelini \& De Marzo, 1981: 287; 1985: 66.

Material: Nepal, Bagmati prov., Nuwakot distr., between Ghopte and Thare Pati, $3200 \mathrm{~m}$, 23-26.IV.1985, leg. A. Smetana, 11 exx. in MHNG, 3 exx. in AC.

Collecting methods: Sifting mosses, plant debris and litter in forest of fir-trees and rhododendrons.

Distribution: Nepal.

Agathidium (s. str.) pusillum Ang. \& Dmz.

Agathidium (s. str.) pusillum Angelini \& De Marzo, 1981: 217; 1984: 551; 1985: 69; 1986: 865.

Material: Nepal, Bagmati prov., Siwapuri distr., Siwapuri Dara, 2500 m, 1.V.1985, leg. A. Smetana, 1 ex. in MHNG.

Collecting methods: Sifting plant debris in forest.

Distribution: Nepal, India (Darjeeling).

Agathidium (s. str.) alatum Ang. \& Dmz.

Agathidium (s. str.) alatum Angelini \& De Marzo, 1981: 209; 1986: 839.

Agathidium (s. str.) alatum: ANGELINI \& COOTER 1986: 37.

Material: Nepal, Bagmati prov., Kathmandu distr., Siwapuri Dara, 2400 m, 29.IV.1985, leg.

A. Smetana, 1 ex. in MHNG.

Collecting methods: Sifting mosses and barks under a fallen tree.

Distribution: Nepal, India (Garhwal). 
Agathidium (s. str.) caelebs Ang. \& Dmz.

Agathidium (s. str.) caelebs Angelini \& De Marzo, 1981: 268; 1985: 42; 1987: 457.

MAterial: Nepal, Bagmati prov., Kathmandu distr., Siwapuri Dara, 2400 m, 30.IV.1985, leg. A. Smetana, 1 ex. in MHNG, 1 ex. in AC.

Collecting methods: Sifting damp plant debris in forest.

Distribution: Nepal.

\section{REFERENCES}

Angelini, F. \& J. Cooter 1986. New species and records of the Genus Agathidium Panzer (Coleoptera, Leiodidae) from South-East Asia. Entomologist's monthly Mag. 122: 37-41.

Angelini, F. \& L. De Marzo 1981. Reports of Agathidium from Himalaya: expeditions of Basel Natural History Museum and Prof. H. Franz (Coleoptera, Leiodidae). Entomologica basil. 6: 187-294.

- 1983a. New species and records of the genus Agathidium Panzer 1797 from Nepal (Insecta: Coleoptera: Leiodidae). Senckenberg. biol. 64: 157-173.

- 1983b. New species and records of Agathidium from Himalaya: expeditions of Basel Natural History Museum (Coleoptera, Leiodidae). Entomologica basil. 8: 153-164.

- 1984. Reports of Agathidium from Darjeeling: expedition 1978 of Geneva Natural History Museum (Coleoptera, Leiodidae). Revue suisse Zool. 91 (3): 545-562.

- 1985. Reports of Agathidium from Central Nepal and North India: expeditions 1979 and 1981 of Geneva Natural History Museum (Coleoptera, Leiodidae). Revue suisse Zool. 92 (1): 33-76.

- 1986. Expeditions 1982, 1983 and 1984 of Geneva Natural History Museum in Nepal. Anisotomini (Coleoptera, Leiodidae). Revue suisse Zool. 93 (4): 827-873.

- 1987. Chorological notes on the genus Agathidium Panzer 1797 from Nepal (Insecta: Coleoptera: Leiodidae). Courier Forsch.-Inst. Senckenberg 93: 455-461. 


\section{$2 \mathrm{BHL}$ Biodiversity Heritage Library}

1989. "Agathidium from Nepal collected by Dr. A. Smetana, with description of a new species (Coleoptera, Leiodidae, Anisotomini)." Revue suisse de zoologie 96, 25-31. https://doi.org/10.5962/bhl.part.82026.

View This Item Online: https://www.biodiversitylibrary.org/item/128795

DOI: https://doi.org/10.5962/bhl.part.82026

Permalink: https://www.biodiversitylibrary.org/partpdf/82026

\section{Holding Institution}

Smithsonian Libraries

\section{Sponsored by}

Biodiversity Heritage Library

\section{Copyright \& Reuse}

Copyright Status: In Copyright. Digitized with the permission of the rights holder.

Rights Holder: Muséum d'histoire naturelle - Ville de Genève License: http://creativecommons.org/licenses/by-nc-sa/3.0/

Rights: https://www.biodiversitylibrary.org/permissions/

This document was created from content at the Biodiversity Heritage Library, the world's largest open access digital library for biodiversity literature and archives. Visit BHL at https://www.biodiversitylibrary.org. 